\title{
The longitudinal association of common susceptibility variants for type 2 diabetes and obesity with fasting glucose level and BMI
}

\author{
Rebecca J Webster ${ }^{1}$, Nicole M Warrington ${ }^{1}$, John P Beilby ${ }^{3,4}$, Timothy M Frayling ${ }^{2}$, Lyle J Palmer ${ }^{1 *}$
}

\begin{abstract}
Background: Variation in the effects of genetic variants on physiological traits over time or with age may alter the trajectories of these traits. However, few studies have investigated this possibility for variants associated with type 2 diabetes or obesity, and these show little consensus. We aimed to characterise the possible longitudinal associations of common diabetes-susceptibility variants in the KCNJ11, PPARG, TCF7L2, IGF2BP2, CDKAL1, SLC3OA8 and HHEX gene loci, with fasting glucose level; and of an obesity-associated variant in the FTO gene, with body mass index (BMI).

Methods: The study analysed data from the Busselton Health Study $(n=4,554)$. Cross-sectional association analyses included family data and used the total association test. Longitudinal association analyses of unrelated participant data $(n=2,864)$ used linear mixed-effects models.

Results: In cross-sectional analyses, we observed associations of the T allele at the IGF2BP2 single nucleotide polymorphism (SNP) rs4402960 with raised fasting glucose $(p=0.045)$, and the A allele at the FTO SNP rs9939609 with raised BMI $(p=0.003)$. Longitudinal analyses showed no significant associations between SNPs and changes in fasting glucose or BMI in the same individuals, either over mean follow-up times of 18.7 and 21.8 years respectively, or with age during adulthood.
\end{abstract}

Conclusions: There was no indication that the effects of common type 2 diabetes variants on fasting glucose varied with age during adulthood or over time.

\section{Background}

Physiological traits are frequently dynamic, varying over time with changing or accumulating environmental and physiological factors. The influence of genotype on these traits may also vary over time through interaction with factors such as age, developmental stage or time-dependent environmental factors. Variation in the effects of genetic variants at different stages of life could significantly alter the trajectories of traits and potentially also the risks of certain diseases. Hence, studies that do not consider the possibility of longitudinal variation in genetic associations may lead to over-simplistic models of variant effects.

\footnotetext{
* Correspondence: Iyle.palmer@uwa.edu.au

'Centre for Genetic Epidemiology and Biostatistics, University of Western Australia, Crawley, WA, Australia

Full list of author information is available at the end of the article
}

Type 2 diabetes (T2D) is a complex disease with numerous risk factors, including a growing number of known genetic susceptibility variants [1-4]. The risk of T2D also rises with increasing age [5]. Some of the intermediate traits of T2D, such as obesity and raised fasting plasma glucose, similarly have complex determinants and indeed both BMI and fasting plasma glucose also tend to increase with age $[6,7]$. These observations raise the question of whether time- or age-varying genetic effects exist that could influence such intermediate traits and thereby T2D risk.

To date, there have been few studies of the longitudinal effects of T2D- or obesity-susceptibility variants. Those that have examined the longitudinal effects of the FTO variant rs9939609 with BMI, give mixed results [8-13]. This SNP has been shown through cross-sectional studies to be robustly associated with raised BMI and, likely as a result of this effect, also linked to the risk of 
T2D [3,11,14-16]. Some longitudinal studies also provide evidence of an age-dependent relationship between rs9939609 and BMI whilst others do not, and some were performed in children and some in adults [8-13].

In the present study, we tested the cross-sectional and longitudinal associations of common genetic variants shown to be associated with the risk of T2D and/or raised BMI [1-4,14,15,17-20], with fasting glucose levels and BMI. The study utilised data from the Busselton Health Study (BHS), in which participants have completed an average of 3.9 phenotypic surveys each, over an average follow-up time of 21.2 years (95\% CI 13.628.8 years). The variants selected were the potassium inwardly-rectifying channel J11 (KCNJ11) single nucleotide polymorphism (SNP) rs5219 (E23K variant); the peroxisome proliferator-activated receptor gamma (PPARG) SNP rs1801282 (Pro12Ala variant); the transcription factor 7-like 2 (TCF7L2) SNP rs7903146; the insulin-like growth factor 2 mRNA binding protein 2 (IGF2BP2) SNP rs4402960; the CDK5 regulatory subunit associated protein1-like 1 (CDKAL1) SNP rs10946398; the solute carrier family 30 (zinc transporter), member 8 (SLC30A8) SNP rs13266634; the hematopoietically expressed homeobox (HHEX) SNP rs1111875; and the fat mass and obesity associated (FTO) SNP rs9939609. These variants represent those with the strongest reported effects on type 2 diabetes risk and, for the FTO variant, BMI.

\section{Methods}

\section{Participants}

Participants were part of the BHS. The BHS includes a series of seven cross-sectional population health surveys of adult residents of the Shire of Busselton in Western Australia, conducted between 1966 and 1990, plus a follow-up study of all survivors of previous surveys, conducted in 1994/95 [21-23]. The population is predominantly European-Australian. The 1994/95 follow-up study involved 4,554 participants from 696 families, and included the collection of blood samples to be used for DNA extraction. Population descriptives for participants surveyed in the 1994/95 follow-up have been presented elsewhere [24] and are reproduced here in Table 1 with kind permission of Springer Science+Business Media. 2,864 unrelated individuals, each of whom had participated in at least one of the eight cross-sectional surveys while aged between 18 and 80 years, were selected from this cohort for longitudinal analysis. A subset of this unrelated sub-cohort, comprising only the 2,583 individuals that reported never having been diagnosed with diabetes and had no fasting glucose level measurements greater than or equal to $7 \mathrm{mmol} / \mathrm{L}$, was also selected, for longitudinal analysis of the fasting glucose outcome variable only. Descriptives for individuals in the unrelated sub-cohort
Table 1 Description of the BHS whole study population at the $1994 / 95$ survey $(n=4,554)^{a}$

\begin{tabular}{ll}
\hline Variable (units) & Mean (SD) \\
\hline Age (years) & $50.6(17.2)$ \\
BMI $\left(\mathrm{kg} / \mathrm{m}^{2}\right)$ & $26.0(4.2)$ \\
Fasting glucose $(\mathrm{mmol} / \mathrm{l})$ & $5.0(1.4)$ \\
Triacylglycerol (mmol/l) & $1.3(0.9)$ \\
LDL (mmol/l) & $3.6(1.0)$ \\
HDL (mmol/l) & $1.4(0.4)$ \\
Total cholesterol (mmol/l) & $5.6(1.1)$ \\
SBP (mmHg) & $124.1(17.9)$ \\
DBP (mmHg) & $74.5(10.2)$ \\
& \\
Male, \% (n) & $44.2(2014)$ \\
Smoking (ever smoked), \% (n) & $17.7(805)$ \\
Diabetes (ever had diabetes), \% (n) & $6.0(271)$ \\
Obesity (BMI $\geq 30), \%(n)$ & $13.3(726)$ \\
Coronary heart disease, \% ( $n$ ) & $16.3(744)$ \\
Metabolic syndrome (IDF definition), \% (n) & $19.1(871)$ \\
Metabolic syndrome (NCEP definition), \% (n) & $15.9(722)$ \\
Lipid-lowering medication, \% (n) & $2.5(116)$ \\
Insulin injections, \% ( $n$ ) & $0.7(31)$ \\
\hline
\end{tabular}

IDF, International Diabetes Federation; NCEP, National Cholesterol Education Program.

a Originally published as Table 1 in Webster RJ, Warrington NM, Weedon MN, Hattersley AT, McCaskie PA, Beilby JP, Palmer LJ, Frayling TM: The association of common genetic variants in the APOA5, LPL and GCK genes with longitudinal changes in metabolic and cardiovascular traits. Diabetologia 2009, 52(1):106-114, ${ }^{\circ}$ Springer-Verlag 2008, reproduced here with kind permission of Springer Science+Business Media.

have been presented elsewhere [24] and are reproduced here in Table 2 with kind permission of Springer Science+ Business Media. The mean number of survey attendances for these individuals was 3.9 (standard error of the mean 0.04 ), over a mean follow-up time of 21.2 years (95\% confidence interval (CI) 13.6-28.8 years). Measurements of BMI, fasting glucose, triacylglycerol and high-density lipoprotein (HDL) levels were taken at 8, 7, 6 and 4 surveys respectively. The subset of unrelated participants had average follow-up times of 21.8, 18.7, 17.0 and 15.1 years for these measurements, respectively. All participants gave written informed consent. The Human Research Ethics Committee of the University of Western Australia approved all study protocols.

\section{Clinical measurements}

Clinical measurements were taken as described previously $[21,22]$. A self-administered questionnaire was used to determine participants' history of smoking, physiciandiagnosed diabetes and use of lipid-lowering medication and insulin injections. Anthropomorphic measurements were taken according to standard clinical procedures. The presence of coronary heart disease was determined using the Rose questionnaire, electrocardiogram and 
Table 2 Description of BHS populations of participants aged 18-80 years, for variables with longitudinal data, at the time of first assessment ${ }^{\mathrm{a}}$

\begin{tabular}{llll}
\hline Variable (units) & $\begin{array}{l}\text { Unrelated population }(\boldsymbol{n}=\mathbf{2 , 8 6 4}), \\
\text { mean (SD) }\end{array}$ & $\begin{array}{l}\text { Unrelated male population }(\boldsymbol{n}=\mathbf{1 , 2 3 4}), \\
\text { mean (SD) }\end{array}$ & $\begin{array}{l}\text { Unrelated female population }(\boldsymbol{n}= \\
\mathbf{1 , 6 3 0}), \text { mean }(\mathrm{SD})\end{array}$ \\
\hline Age (years) & $37.8(11.6)$ & $38.1(11.6)$ & $37.6(11.6)$ \\
$\mathrm{BMI}\left(\mathrm{kg} / \mathrm{m}^{2}\right)$ & $24.3(3.6)$ & $24.9(3.2)$ & $23.8(3.8)$ \\
$\begin{array}{l}\text { Fasting glucose } \\
\text { (mmol/l) }\end{array}$ & $5.0(1.1)$ & $5.2(1.4)$ & $4.8(0.8)$ \\
$\begin{array}{l}\text { Triacylglycerol } \\
(\mathrm{mmol} / \mathrm{l})\end{array}$ & $1.2(0.8)$ & $1.4(1.0)$ & $1.1(0.6)$ \\
$\mathrm{HDL}(\mathrm{mmol} / \mathrm{l})$ & $1.4(0.4)$ & $1.3(0.3)$ & $1.6(0.4)$ \\
$\begin{array}{l}\text { Total cholesterol } \\
(\mathrm{mmol} / \mathrm{l})\end{array}$ & $5.6(1.2)$ & $5.6(1.2)$ & $5.6(1.2)$
\end{tabular}

${ }^{a}$ Originally published as Table 2 in Webster RJ, Warrington NM, Weedon MN, Hattersley AT, McCaskie PA, Beilby JP, Palmer LJ, Frayling TM: The association of common genetic variants in the APOA5, LPL and GCK genes with longitudinal changes in metabolic and cardiovascular traits. Diabetologia 2009, 52(1):106-114, - Springer-Verlag 2008, reproduced here with kind permission of Springer Science+Business Media.

self-reported history of physician-diagnosed angina or myocardial infarction.

\section{Laboratory measurements}

Fasting glucose, insulin and lipid (HDL, low-density lipoprotein (LDL) and triacylglycerol) levels were measured from fasting venous blood samples as described previously [25]. The HOMA Calculator [26] was used to calculate homeostatic model assessment (HOMA) scores to be used as indicators of insulin resistance. These were HOMA2-\%B (steady-state beta cell function) and HOMA2-\%S (insulin sensitivity) [27,28].

\section{Genes and genotyping}

The SNPs selected for this study were the KCNJ11 SNP rs5219; the PPARG SNP rs1801282; the TCF7L2 SNP rs7903146; the IGF2BP2 SNP rs4402960; the CDKAL1 SNP rs10946398; the SLC30A8 SNP rs13266634; the HHEX SNP rs1111875; and the FTO SNP rs9939609. These SNPs were genotyped for all 4,554 study participants using TaqMan probes designed and supplied by Applied Biosystems, Scoresby, VIC Australia. All primer sequences and experimental conditions are available from the authors on request. Genotyping was performed by the PathWest Molecular Genetics Service, Nedlands, WA, Australia.

\section{Statistical analyses}

The statistical analysis approach and methods used for this study are as described in detail elsewhere [24]. Tests of Hardy-Weinberg equilibrium were conducted using an exact test implemented in the statistical analysis package, $R$ [29].

Cross-sectional association analyses were performed using 1994/95 survey data from the whole cohort of 4,554 participants. The continuous outcome variables tested were HDL, LDL, triacylglycerol, systolic blood pressure (SBP), diastolic blood pressure (DBP), fasting glucose and fasting insulin levels, HOMA2-\%B, HOMA2-\%S, and BMI. With the exception of LDL and DBP, all were natural log-transformed prior to analysis. The binary outcome variables tested were 'history of diabetes', a variable indicating whether a participant had reported ever been diagnosed with diabetes at any survey, and 'obesity', a variable indicating whether a participant was obese (BMI $\geq 30$ ) at the 1994/95 survey. Selection of covariates for each outcome involved the use of generalised linear models to model the effects of a set of multiple relevant phenotypes on the outcome in the unrelated sub-cohort, using the SimHap v1.0.0 program http://www.genepi.org.au/simhap.html, and a process of stepwise elimination to remove those not associated with the outcome. Models derived using this procedure were called full covariate models. Simple covariate models including only sex and age were also used for analyses. Cross-sectional association analyses of continuous outcomes employed the total association test as implemented in the QTDT v2.6.0 program [30]. This test models the effects of covariates on continuous outcomes within families. Between-individual variance was modelled by environmental, polygenic and additive major-gene-effect variance components. Cross-sectional analysis of the binary obesity outcome employed the transmission disequilibrium test (TDT) as implemented in the QTDT v2.6.0 program. As there were too few participants with a history of diabetes in the whole cohort to enable a TDT of family data to be performed for all SNPs, cross-sectional analyses of the history of diabetes outcome were performed on the sub-cohort of unrelated participants aged 18-80 years, using the SimHap v1.0.0 program to fit generalised linear models.

Longitudinal association analyses were performed using data from the sub-cohort of unrelated participants aged 18-80 years and, for the case of the fasting glucose outcome variable only, on the non-diabetic subset. The outcome variables tested were fasting glucose, HDL and 
triacylglycerol levels, and BMI, which were natural logtransformed prior to analysis. The age, time and BMI covariates were mean-centred. Longitudinal association analyses were conducted using linear mixed-effects models [31] with time $\times$ SNP and age $\times$ SNP interaction terms, using the SimHap program. Covariates were selected through a process of stepwise elimination as described above. Genotypes were coded into three classes (major allele homozygote $=0$, heterozygote $=1$ or minor allele homozygote $=2$ ) and analysed under a co-dominant genetic model. The results were used to identify significant associations and investigate the most appropriate genetic model for each case. The results of the co-dominant model analyses are presented due to the difficulty in assigning a more appropriate model in the majority of cases.

\section{Statistical power}

All power calculations were performed using the Quanto v1.2.3 software [32]. For all SNPs, analyses of BMI and fasting glucose had at least $80 \%$ power at an alpha level of $p=0.05$ to detect a difference in beta coefficient of 0.010 and 0.013 (log-transformed units) respectively, for the case of longitudinal analyses of the unrelated subcohort, and 0.014 and 0.011 (log-transformed units) respectively, for the case of cross-sectional analyses of the whole cohort, under additive genetic models.

\section{Results}

\section{Population characteristics}

Genotypic and allelic frequencies for all eight SNPs in the BHS populations are given in Additional file 1: Electronic Supplementary Material (ESM) Table 1. No significant deviation of allele frequencies from Hardy-Weinberg equilibrium was observed in either the whole study cohort or the unrelated sub-cohort for any of the SNPs. Call rates for each SNP, validated through sequencing, are also given in Additional file 1: ESM Table 1. Call rates exceeded $99 \%$ for all SNPs.

\section{Cross-sectional association of SNPs with metabolic and cardiovascular traits}

The results of cross-sectional total association analyses of the whole cohort $(n=4,554)$ at the 1994/95 survey for the fasting glucose and BMI outcomes are given in Table 3. In analyses using full covariate models, we observed that the T T2D-risk allele at the IGF2BP2 SNP rs4402960 was associated with raised fasting glucose level $(p=0.045)$, and that the A obesity-risk allele at the FTO SNP rs9939609 was associated with raised BMI $(p=0.003)$. Similar results were obtained using the simple covariate model. In multivariate cross-sectional analyses of traits in the sub-cohort of unrelated individuals at the 1994/95 survey, we observed that, under an additive genetic model, rs4402960 explained $0.1 \%$ of variation in fasting glucose level in unrelated non-diabetic participants $(n=2,583)$. There was no significant association between BMI and rs9939609 in the unrelated sub-cohort at the $1994 / 95$ survey $(n=2,864)$, and the percentage of variance in BMI explained by rs9939609 in this sub-cohort was estimated to be $0 \%$.

The results of cross-sectional total association analyses performed with additional metabolic and cardiovascular outcomes are given in Additional file 1: ESM Table 2. In analyses using full covariate models, we observed that the C T2D-risk allele at the CDKAL1 SNP rs10946398 was associated with reduced HOMA2-\%B $(p=0.01)$; that the major C T2D-risk allele at the SLC30A8 SNP rs13266634 was associated with reduced HOMA2-\%B $(p=0.03)$; that the major $\mathrm{C}$ T2D-risk allele at the PPARG SNP rs1801282 was associated with reduced HOMA2-\%S ( $p=$ $0.01)$ and raised fasting insulin level $(p=0.01)$; that the major G T2D-risk allele at the HHEX SNP rs1111875 was associated with raised HOMA2-\%S $(p=0.01)$ and reduced fasting insulin level $(p=0.01)$; that the T T2Drisk allele at the KCNJ11 SNP rs5219 was associated with reduced $\mathrm{BMI}(p=0.001)$; that the $\mathrm{T} \mathrm{T} 2 \mathrm{D}$-risk allele the TCF7L2 SNP at rs7903146 was associated with raised triacylglycerol $(p=0.01)$ and LDL levels $(p=0.01)$; and that the $\mathrm{T}$ T2D-risk allele at the IGF2BP2 SNP rs4402960 was associated with raised triacylglycerol level $(p=0.001)$. Similar results were obtained using the simple covariate model (data not shown).

The results of cross-sectional association analyses of the binary outcomes history of diabetes, and obesity are given in Additional file 1: ESM Table 3. The C T2D-risk allele at the PPARG SNP rs1801282, the $\mathrm{T}$ T2D-risk allele at the TCF7L2 SNP rs7903146, and the T T2D-risk allele at the IGF2BP2 SNP rs4402960 were significantly associated with T2D $(p=0.0496, p=$ $0.039, p=0.022$, respectively), with odds ratios of 1.46 (95\% CI 1.00-2.12), 1.27 (95\% CI 1.01-1.60) and 1.30 (95\% CI 1.04-1.63) per risk allele, respectively. There was no significant association of the KCNJ11 SNP rs5219, the CDKAL1 SNP rs10946398, the SLC30A8 SNP rs13266634, the HHEX SNP rs1111875, or the FTO SNP rs9939609 with T2D. Analysis of the obesity outcome showed that the FTO SNP rs9939609 was not significantly associated with obesity $(p=0.457)$. Similar results were obtained using the simple covariate model (data not shown).

\section{Longitudinal association of SNPs with metabolic and cardiovascular traits}

The results of longitudinal association analyses for the fasting glucose level and BMI outcomes are given in Table 4. For each of these analyses, fitted values, calculated according to the co-dominant genetic models 
Table 3 Results of cross-sectional association analyses of fasting glucose and BMI ${ }^{\mathrm{a}}$

\begin{tabular}{|c|c|c|c|c|c|c|}
\hline \multirow[b]{2}{*}{ Gene } & \multirow[b]{2}{*}{ SNP } & \multirow[b]{2}{*}{ Risk allele (frequency) } & \multicolumn{2}{|c|}{ Full covariate model ${ }^{b}$} & \multicolumn{2}{|c|}{ Simple covariate model $^{c}$} \\
\hline & & & Per risk allele effect size & $p$ & Per risk allele effect size & $p$ \\
\hline \multicolumn{7}{|c|}{ Fasting glucose } \\
\hline KCNJ11 & rs5219 & $\top(0.363)$ & 0.001 & 0.70 & -0.001 & 0.75 \\
\hline PPARG & rs1801282 & $C(0.883)$ & 0.003 & 0.56 & 0.011 & 0.05 \\
\hline TCF7L2 & rs7903146 & $\mathrm{T}(0.303)$ & 0.003 & 0.44 & 0.006 & 0.12 \\
\hline IGF2BP2 & rs4402960 & $\mathrm{T}(0.304)$ & 0.007 & $0.045^{*}$ & 0.011 & $0.01^{*}$ \\
\hline CDKAL1 & rs10946398 & $C(0.303)$ & 0.006 & 0.08 & 0.003 & 0.42 \\
\hline SLC30A8 & rs13266634 & $C(0.699)$ & 0.007 & 0.05 & 0.005 & 0.18 \\
\hline HHEX & rs1111875 & $G(0.584)$ & -0.002 & 0.51 & -0.003 & 0.40 \\
\hline \multicolumn{7}{|l|}{ BMI } \\
\hline FTO & rs9939609 & A (0.409) & 0.009 & $0.003^{*}$ & 0.013 & $0.0003^{*}$ \\
\hline
\end{tabular}

${ }^{a}$ Analyses were conducted on data from the whole study population $(n=4,554)$ at the 1994/95 survey.

${ }^{b}$ Phenotype adjustments, full covariate model:

Fasting glucose: sex, age, age squared, BMI, fasting insulin, SBP, history of diabetes.

BMl: sex, age, age squared, fasting insulin, HDL, SBP, DBP.

' Phenotype adjustments for all outcomes, simple covariate model: sex, age.

${ }^{*} p<0.05$.

used, are plotted by genotype group against age in Figures 1 and 2.

For longitudinal analyses of the fasting glucose level outcome, the SNP simple effects (non-interaction) results showed no significant associations of any of the seven SNPs with fasting glucose in the unrelated subcohort (data not shown). The SNP interaction results showed no strong evidence of effect sizes varying with age (from 18-80 years) or time (from 1975-1994/5). Analysis of rs1111875 with fasting glucose under a codominant model showed a significant association of the age $\times$ rs1111875 (heterozygote vs major homozygote) interaction term with fasting glucose level (Table 4; $p=$ 0.03), suggesting that one copy of the A non-risk allele at rs1111875 increases fasting glucose level with increasing age. However, under an additive genetic model, deemed to be the most likely genetic model for this particular association based on the co-dominant model results, the age $\times$ rs1111875 interaction term was not significantly associated with fasting glucose level, indicating that there is no significant overall linear trend in the effect size of rs1111875 genotype on fasting glucose level with age.

In longitudinal analyses of BMI, rs9939609 simple effects were found to be significant, with the rs 9939609 minor homozygote vs major homozygote term being significantly associated with raised BMI under a co-dominant model $(p=0.003)$, and the rs9939609 term being significantly associated with raised BMI under the bestfitting recessive model $(p=0.004)$. This indicates that the A allele at rs9939609 is significantly associated with raised BMI in the unrelated sub-cohort, when data from all surveys are considered. However, there was no evidence for longitudinal variation in the effect size of rs9939609 genotype on BMI, either over time or with age from 18-80 years.

Longitudinal association analysis results for lipid level and BMI outcomes with all SNPs are given in Additional file 1: ESM Table 4. We observed some evidence for increasing effect sizes of the $\mathrm{T}$ risk alleles at rs7903146 and rs4402960 on triacylglycerol level with time and age respectively, and for a decreasing effect size of the $C$ risk allele at rs13266634 on triacylglycerol level with age. We also observed some evidence that the effect sizes of the risk C alleles at rs1801282 and rs13266634 on HDL varied with both age and time, a decreasing effect with age and increasing effect with time for the case of rs1801282, and an increasing effect with age and decreasing effect with time for the case of rs13266634. There was also some evidence that the effect size of the G risk allele at rs1111875 on BMI decreased with age and increased with time.

\section{Discussion}

While the number of genetic variants confirmed to be associated with $\mathrm{T} 2 \mathrm{D}$ is growing, the relationships between these variants and T2D intermediate phenotypes are yet to be fully characterised, particularly longitudinally. In this study, we investigated the cross-sectional and longitudinal associations of seven T2D-susceptibility variants in the KCNJ11, PPARG, TCF7L2, IGF2BP2, CDKAL1, SLC3OA8 and HHEX genes with fasting glucose level, and of another in the FTO gene with BMI, in a large, population-based European-Australian cohort.

Our cross-sectional analyses showed that, of the seven SNPs analysed with the fasting glucose outcome, only the IGF2BP2 SNP rs4402960 showed a significant result, the $\mathrm{T}$ allele at this SNP being nominally associated with 
Table 4 Results of longitudinal association analyses of fasting glucose and BMI

\begin{tabular}{|c|c|c|c|c|c|c|}
\hline \multirow[b]{2}{*}{ Gene } & \multirow[b]{2}{*}{$\begin{array}{l}\text { SNP (Risk allele, } \\
\text { frequency) }\end{array}$} & \multirow[b]{2}{*}{ Factor } & \multicolumn{2}{|l|}{ Age $\times$ SNP interaction } & \multicolumn{2}{|l|}{ Time $\times$ SNP interaction } \\
\hline & & & Beta $(95 \% \mathrm{Cl})$ & $p$ & Beta $(95 \% \mathrm{Cl})$ & $p$ \\
\hline \multicolumn{7}{|c|}{ Fasting glucose $^{b}\left(\log _{e}[\mathrm{mmol} / \mathrm{l}]\right)$} \\
\hline \multirow[t]{3}{*}{ KCNJ11 } & rs5219 & $\mathrm{CC}$ & Baseline & & & \\
\hline & $(T, 0.355)$ & $\mathrm{CT}$ & $7.0 \times 10^{-5}\left(-4.6 \times 10^{-4}, 6.0 \times 10^{-4}\right)$ & 0.79 & $-5.3 \times 10^{-4}\left(-1.3 \times 10^{-3}, 2.6 \times 10^{-4}\right)$ & 0.19 \\
\hline & & $\pi$ & $-4.3 \times 10^{-4}\left(-1.2 \times 10^{-3}, 3.3 \times 10^{-4}\right)$ & 0.27 & $-6.8 \times 10^{-4}\left(-1.8 \times 10^{-3}, 4.8 \times 10^{-4}\right)$ & 0.25 \\
\hline \multirow[t]{3}{*}{ PPARG } & rs1801282 & $\mathrm{CC}$ & Baseline & & & \\
\hline & $(C, 0.881)$ & $C G$ & $8.0 \times 10^{-5}\left(-5.2 \times 10^{-4}, 6.8 \times 10^{-4}\right)$ & 0.79 & $-3.6 \times 10^{-4}\left(-1.3 \times 10^{-3}, 5.4 \times 10^{-4}\right)$ & 0.43 \\
\hline & & GG & $-8.8 \times 10^{-4}\left(-3.0 \times 10^{-3}, 1.2 \times 10^{-3}\right)$ & 0.41 & $3.7 \times 10^{-4}\left(-2.8 \times 10^{-3}, 3.6 \times 10^{-3}\right)$ & 0.82 \\
\hline \multirow[t]{3}{*}{ TCF7L2 } & rs7903146 & CC & Baseline & & & \\
\hline & $(T, 0.300)$ & $\mathrm{CT}$ & $-1.2 \times 10^{-4}\left(-6.3 \times 10^{-4}, 4.0 \times 10^{-4}\right)$ & 0.65 & $-3.2 \times 10^{-4}\left(-1.1 \times 10^{-3}, 4.5 \times 10^{-4}\right)$ & 0.41 \\
\hline & & $\pi$ & $7.3 \times 10^{-4}\left(-1.6 \times 10^{-4}, 1.6 \times 10^{-3}\right)$ & 0.11 & $5.6 \times 10^{-4}\left(-8.0 \times 10^{-4}, 1.9 \times 10^{-3}\right)$ & 0.42 \\
\hline \multirow[t]{3}{*}{ IGF2BP2 } & rs4402960 & GG & Baseline & & & \\
\hline & $(T, 0.314)$ & GT & $-3.8 \times 10^{-5}\left(-5.5 \times 10^{-4}, 4.8 \times 10^{-4}\right)$ & 0.89 & $6.3 \times 10^{-4}\left(-1.5 \times 10^{-4}, 1.4 \times 10^{-3}\right)$ & 0.12 \\
\hline & & $\pi$ & $4.7 \times 10^{-4}\left(-4.1 \times 10^{-4}, 1.4 \times 10^{-3}\right)$ & 0.30 & $-4.0 \times 10^{-4}\left(-1.7 \times 10^{-3}, 9.1 \times 10^{-4}\right)$ & 0.55 \\
\hline \multirow[t]{3}{*}{ CDKAL1 } & rs10946398 & AA & Baseline & & & \\
\hline & $(C, 0.308)$ & $A C$ & $4.9 \times 10^{-5}\left(-4.7 \times 10^{-4}, 5.7 \times 10^{-4}\right)$ & 0.85 & $2.1 \times 10^{-4}\left(-5.7 \times 10^{-4}, 9.9 \times 10^{-4}\right)$ & 0.60 \\
\hline & & CC & $-3.3 \times 10^{-4}\left(-1.2 \times 10^{-3}, 5.0 \times 10^{-4}\right)$ & 0.43 & $-3.6 \times 10^{-4}\left(-1.6 \times 10^{-3}, 9.1 \times 10^{-4}\right)$ & 0.58 \\
\hline \multirow[t]{3}{*}{ SLC30A8 } & rs13266634 & $\mathrm{CC}$ & Baseline & & & \\
\hline & $(C, 0.696)$ & $\mathrm{CT}$ & $2.4 \times 10^{-5}\left(-4.9 \times 10^{-4}, 5.4 \times 10^{-4}\right)$ & 0.93 & $1.4 \times 10^{-4}\left(-6.4 \times 10^{-4}, 9.1 \times 10^{-4}\right)$ & 0.73 \\
\hline & & $\pi$ & $8.0 \times 10^{-4}\left(-5.2 \times 10^{-5}, 1.7 \times 10^{-3}\right)$ & 0.07 & $-1.2 \times 10^{-4}\left(-1.4 \times 10^{-3}, 1.2 \times 10^{-3}\right)$ & 0.86 \\
\hline \multirow[t]{3}{*}{ HHEX } & rs1111875 & GG & Baseline & & & \\
\hline & $(G, 0.578)$ & GA & $6.1 \times 10^{-4}\left(6.3 \times 10^{-5}, 1.2 \times 10^{-3}\right)$ & $0.03^{*}$ & $-2.3 \times 10^{-4}\left(-1.0 \times 10^{-3}, 6.0 \times 10^{-4}\right)$ & 0.59 \\
\hline & & AA & $-2.3 \times 10^{-4}\left(-9.3 \times 10^{-4}, 4.8 \times 10^{-4}\right)$ & 0.53 & $2.4 \times 10^{-4}\left(-8.2 \times 10^{-4}, 1.3 \times 10^{-3}\right)$ & 0.65 \\
\hline \multicolumn{7}{|c|}{$\mathrm{BMI}^{\mathrm{b}}\left(\log _{\mathrm{e}}\left[\mathrm{kg} / \mathrm{m}^{2}\right]\right)$} \\
\hline \multirow[t]{3}{*}{ FTO } & rs9939609 & $\pi$ & Baseline & & & \\
\hline & $(A, 0.402)$ & TA & $2.6 \times 10^{-4}\left(-4.7 \times 10^{-4}, 9.9 \times 10^{-4}\right)$ & 0.49 & $2.1 \times 10^{-5}\left(-7.7 \times 10^{-4}, 8.1 \times 10^{-4}\right)$ & 0.96 \\
\hline & & AA & $-2.0 \times 10^{-5}\left(-1.0 \times 10^{-3}, 9.9 \times 10^{-4}\right)$ & 0.97 & $-2.8 \times 10^{-4}\left(-1.4 \times 10^{-3}, 8.1 \times 10^{-4}\right)$ & 0.61 \\
\hline
\end{tabular}

${ }^{a}$ BMI outcome analyses were conducted on data from unrelated participants aged 18-80 years $(n=2,864)$. Fasting glucose outcome analyses were conducted on data from the subset of non-diabetic participants $(n=2,583)$. Results are for age $\times$ SNP and time $\times$ SNP interaction terms with co-dominant genetic models.

${ }^{\mathrm{b}}$ Phenotype adjustments:

Fasting glucose: sex, age, BMI, age at first survey, time of survey.

BMl: sex, age, age $\times$ sex, smoking status, age at first survey, time of survey.

${ }^{*} p<0.05$.

raised fasting glucose $(p=0.045)$. Though some previous studies have reported significant associations of rs4402960, rs7903146 and rs13266634 with raised fasting glucose [33-36], others find no significant associations between these three SNPs and fasting glucose in their populations [33,34,37-40]. Studies of the SNPs rs5219, rs1801282, rs10946398 and rs1111875 have also shown no significant associations with fasting glucose $[17,33,34,38,40-44]$. Rather, the majority of evidence from previous studies suggests that these seven SNPs alter T2D susceptibility through effects on insulin sensitivity (rs1801282 [45]) or pancreatic beta cell function (rs5219, rs7903146, rs10946398, rs4402960, rs13266634 and rs1111875 [34,36,38,46-52]). Indeed, we did observe associations of the risk allele at the PPARG SNP rs1801282 with lower HOMA2-\% $(p=0.01)$, and of the risk alleles at the CDKAL1 SNP rs10946398 and the SLC30A8 SNP rs13266634 with lower HOMA2-\%B ( $p=0.01$ and $p=0.03$, respectively). Fasting glucose level may reflect abnormalities in insulin sensitivity and beta cell function, and is a useful clinical indicator of diabetes. However, it is dependent on a number of other factors, e.g. the site of insulin insensitivity [53], which may have influenced the results here. It may also be that effects on fasting glucose are more subtle than may be detected with the available power. We also did not observe significant associations of the SNPs rs5219, rs10946398, rs1111875 or rs9939609 with T2D, likely due in part to the small number of diabetic participants in our cohort.

Associations may also be more difficult to detect if SNP effects vary with factors such as other gene variants, lifestyle factors and age. If a SNP has an age-varying effect on a particular trait, such as an effect to raise fasting glucose level as of middle age for example, then crosssectional analysis of participants of all ages may miss the association. On the other hand, longitudinal analysis may 

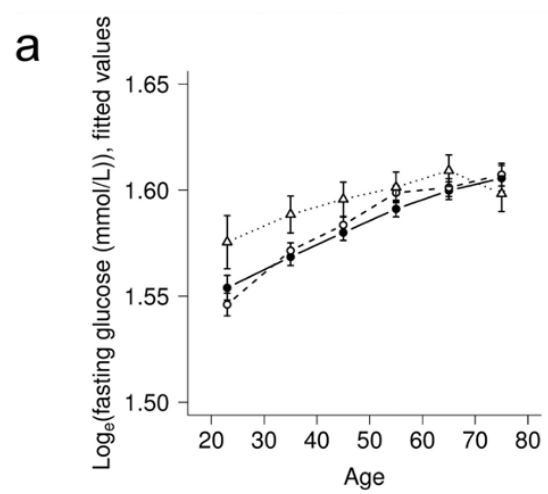

b

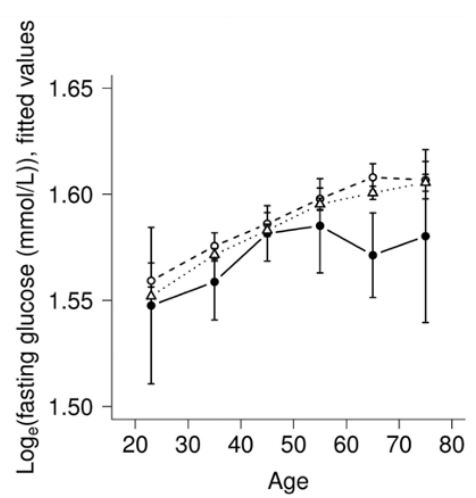

C

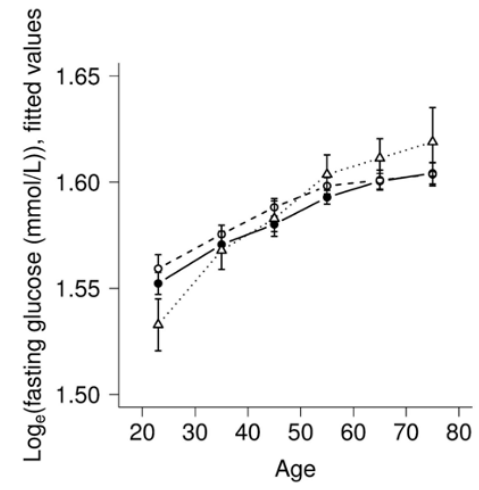

e
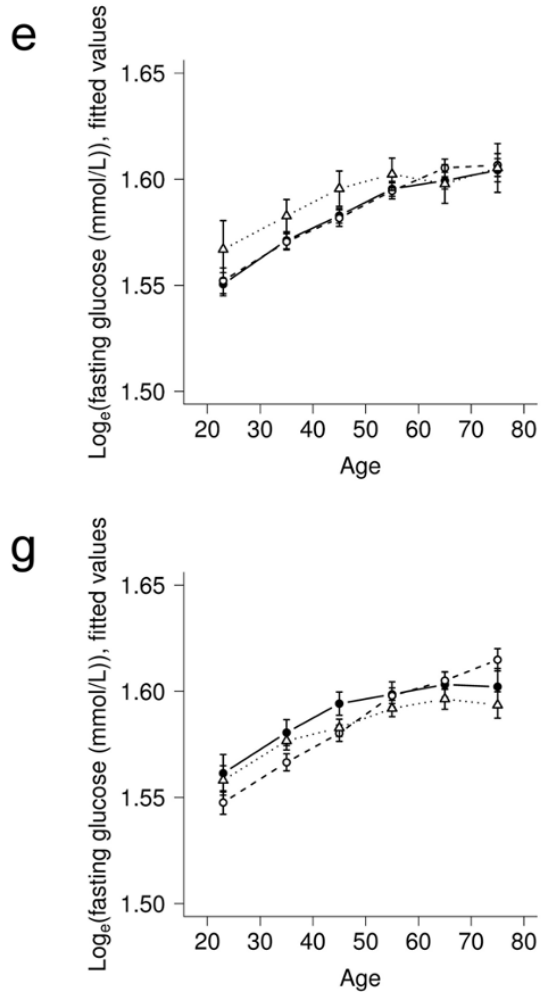

d

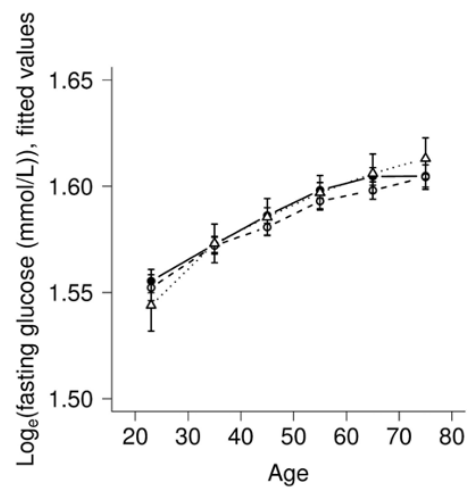

f

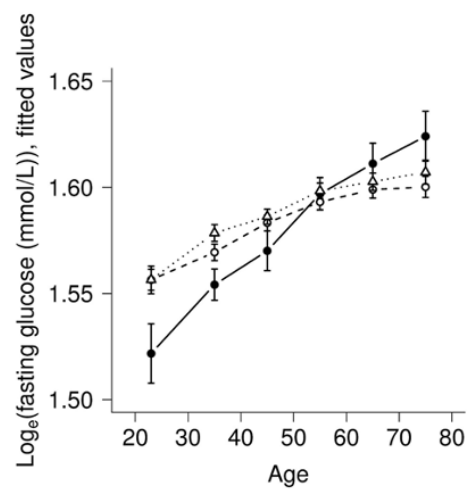

Figure 1 Variation with age of adjusted, natural log-transformed fasting glucose by genotype. Data is from unrelated, non-diabetic participants aged 18-80 years ( $n=2,583$ ), for seven SNPs: (a) KCNJ11 SNP rs5219, (b) PPARG SNP rs1801282, (c) TCF7L2 SNP rs7903146, (d) IGF2BP2 SNP rs4402960, (e) CDKAL1 SNP rs10946398, (f) SLC30A8 SNP rs13266634, (g) HHEX SNP rs1111875. Values were fitted using co-dominant genetic models. 


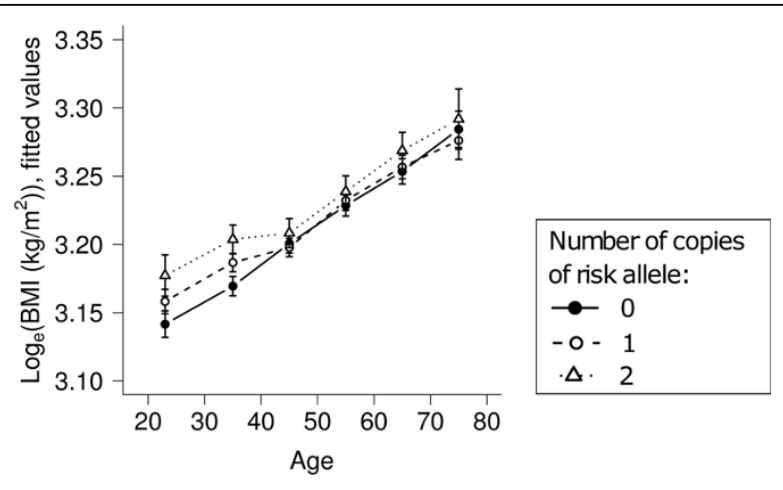

Figure 2 Variation with age of adjusted, natural logtransformed BMI by rs9939609 genotype. Data is from unrelated participants aged $18-80$ years $(n=2,864)$. Values were fitted using a co-dominant genetic model.

still identify the relationship, by examining the association of the combination of SNP allele and age with phenotype in aging individuals, through a SNP $\times$ age interaction term. However, in our longitudinal analyses of SNPs with fasting glucose level, we found no evidence of changes in associations either with age or over time, indicating that these SNPs are not involved in the agerelated increase in fasting glucose level, and that their effects are not influenced by any environmental factors that have changed over the $\sim 20$ year time period examined. The curves of Figure 1 depict these results, generally showing no significant differences in the rates at which fasting glucose level increases with age for the three genotype groups of each SNP, although it is important to note again that we did not see strong evidence for cross-sectional differences.

Our investigation of the FTO SNP rs9939609 showed no significant association with obesity. However, we did confirm that the A allele at rs9939609 was significantly associated with raised BMI, both in cross-sectional analyses of the whole adult study population $(p=0.003)$, and in analyses of the unrelated sub-cohort performed across all surveys $(p=0.004)$. The association between FTO variants and BMI is not in doubt, and has been described both in childhood and old age [11,14-16,54]. For the rs9939609 SNP, an effect size of about $0.4 \mathrm{~kg} /$ $\mathrm{m}^{2}$ per susceptibility allele has been reported [14]. But does this effect size alter with age? We found no significant evidence of this in our analysis of the rs9939609 SNP in the unrelated study population. Several other studies of the longitudinal effects of FTO on BMI have been conducted. Some of these have reported different effects at different ages, but these findings were often limited to one sex or another subgroup after a primary analysis, and chance may have influenced these results [8,11-13]. The evidence that FTO has different effects on BMI at different ages or at different times is therefore weak and further studies are needed.

Differences between the findings of this and other studies may have arisen from numerous sources. Most likely chance has played a strong role. Moreover, this study is underpowered to detect small to moderate genetic effects. Hence, the failure to observe significant associations must be interpreted in this light. Differences in factors that may interact with genotype but were not controlled for, e.g. lifestyle factors such as diet and physical activity, may also have influenced the results, as may have differences in the ethnic compositions of the cohorts studied. The risk allele frequencies of all eight SNPs in the BHS cohort studied here (Additional file 1: ESM Table 1) are comparable to those in European populations, as reported in the dbSNP database http:// www.ncbi.nlm.nih.gov/projects/SNP/.

It is clear that further studies are required to assess the validity of our longitudinal findings. These would ideally address the issues of analytic power and additional covariates, and test the generalisability of our results to populations from diverse ethnic backgrounds. In addition, though the average follow-up times of 18.7 years for fasting glucose level and 21.8 years for BMI enable an extended longitudinal analysis to be conducted, they cannot provide as complete a picture of age-related changes as would come from a study that followed participants through from youth to old age. However, to our knowledge, few longer running longitudinal surveys of the same individuals are able to address these longitudinal questions, and the BHS provides phenotypic data that is particularly comprehensive. The understanding of the function of the T2D-susceptibility SNPs studied here would also benefit from longitudinal analysis of additional metabolic traits, such as glucose tolerance test 30 minute and 2 hour glucose levels, which would provide further information on their relationship to impaired glucose tolerance.

\section{Conclusions}

In conclusion, the results of this study showed no indication that the effects of seven common T2D susceptibility variants on fasting glucose level or the effect of the FTO SNP rs9939609 on BMI varied with age during adulthood or over time. However, the results should be interpreted with caution due to power considerations. The potential consequences of longitudinal associations on phenotypic traits and their treatment across the lifespan highlight the need for replication and further characterisation studies. 


\section{Additional material}

Additional file 1: Word document (376 k) containing Electronic Supplementary Material (ESM) Tables 1, 2, 3 and 4.

\section{List of abbreviations}

BHS: Busselton Health Study; BMI: body mass index; Cl: confidence interval; DBP: diastolic blood pressure; HDL: high-density lipoprotein; HOMA: homeostatic model assessment; LDL: low-density lipoprotein; SBP: systolic blood pressure; SNP: single nucleotide polymorphism; T2D: type 2 diabetes.

\section{Competing interests}

The authors declare that they have no competing interests.

\section{Authors' contributions}

RW carried out the statistical analyses and drafted the manuscript. NW contributed statistical advice for the cross-sectional and longitudinal analyses. JB was involved in data collection and laboratory analysis. TF participated in the design and coordination of the study and helped to draft the manuscript. LP participated in the design and coordination of the study. All authors read and approved the final manuscript.

\section{Acknowledgements}

The authors thank the people of the Busselton Community for their participation in this study, the Busselton Population Medical Research Foundation and the many colleagues who assisted in the collection of these data. We also acknowledge the generous support for the 1994/95 follow-up study from Healthway, Western Australia. The Busselton population studies are supported by The Great Wine Estates of the Margaret River region of Western Australia. We also gratefully acknowledge the assistance of the Western Australian Genetic Epidemiology Resource and the Western Australian DNA Bank (National Health and Medical Research Council of Australia National Enabling Facilities), and the Australian Medical Bioinformatics Resource (a National Health and Medical Research Council of Australia Medical Bioinformatics Genomics Proteomics Program).

\section{Author details}

${ }^{1}$ Centre for Genetic Epidemiology and Biostatistics, University of Western Australia, Crawley, WA, Australia. ${ }^{2}$ Genetics of Complex Traits, Peninsula Medical School, University of Exeter, Exeter, UK. ${ }^{3}$ Pathology and Laboratory Medicine, University of Western Australia, Crawley, WA, Australia. ${ }^{4}$ Molecular Genetics, PathWest Laboratory Medicine, Nedlands, WA, Australia.

\section{Received: 24 March 2010 Accepted: 8 October 2010}

Published: 8 October 2010

\section{References}

1. Genome-wide association study of 14,000 cases of seven common diseases and 3,000 shared controls. Nature 2007, 447:661-678.

2. Sladek R, Rocheleau G, Rung J, Dina C, Shen L, Serre D, Boutin P, Vincent D, Belisle A, Hadjadj S, et al: A genome-wide association study identifies novel risk loci for type 2 diabetes. Nature 2007, 445:881-885.

3. Scott $L$, Mohlke KL, Bonnycastle LL, Willer CJ, Li Y, Duren WL, Erdos MR, Stringham HM, Chines PS, Jackson AU, et al: A genome-wide association study of type 2 diabetes in Finns detects multiple susceptibility variants. Science 2007, 316:1341-1345.

4. Zeggini E, Weedon MN, Lindgren CM, Frayling TM, Elliott KS, Lango $H$, Timpson NJ, Perry JR, Rayner NW, Freathy RM, et al: Replication of genome-wide association signals in UK samples reveals risk loci for type 2 diabetes. Science 2007, 316:1336-1341.

5. Rahman M, Simmons RK, Harding AH, Wareham NJ, Griffin SJ: A simple risk score identifies individuals at high risk of developing Type 2 diabetes: a prospective cohort study. Fam Pract 2008, 25:191-196.

6. Folsom AR, Jacobs DR Jr, Wagenknecht LE, Winkhart SP, Yunis C, Hilner JE, Savage PJ, Smith DE, Flack JM: Increase in fasting insulin and glucose over seven years with increasing weight and inactivity of young adults.
The CARDIA Study. Coronary Artery Risk Development in Young Adults. Am J Epidemiol 1996, 144:235-246.

7. Wilsgaard T, Arnesen E: Change in serum lipids and body mass index by age, sex, and smoking status: the Tromso study 1986-1995. Ann Epidemiol 2004, 14:265-273.

8. Qi L, Kang K, Zhang C, van Dam RM, Kraft P, Hunter D, Lee CH, Hu FB: Fat mass-and obesity-associated (FTO) gene variant is associated with obesity: longitudinal analyses in two cohort studies and functional test. Diabetes 2008, 57:3145-3151.

9. Haworth CM, Carnell S, Meaburn EL, Davis OS, Plomin R, Wardle J: Increasing heritability of BMI and stronger associations with the FTO gene over childhood. Obesity (Silver Spring) 2008, 16:2663-2668.

10. Hakanen M, Raitakari OT, Lehtimaki T, Peltonen N, Pahkala K, Sillanmaki L, Lagstrom H, Viikari J, Simell O, Ronnemaa T: FTO genotype is associated with body mass index after the age of seven years but not with energy intake or leisure-time physical activity. J Clin Endocrinol Metab 2009, 94:1281-1287.

11. Lara-Castro C, Doud EC, Tapia PC, Munoz AJ, Fernandez JR, Hunter GR, Gower BA, Garvey WT: Adiponectin multimers and metabolic syndrome traits: relative adiponectin resistance in African Americans. Obesity (Silver Spring) 2008, 16:2616-2623

12. Jess T, Zimmermann E, Kring SI, Berentzen T, Holst C, Toubro S, Astrup A, Hansen T, Pedersen O, Sorensen TI: Impact on weight dynamics and general growth of the common FTO rs9939609: a longitudinal Danish cohort study. Int J Obes (Lond) 2008, 32:1388-1394.

13. Marvelle AF, Lange LA, Qin L, Adair LS, Mohlke KL: Association of FTO with obesity-related traits in the Cebu Longitudinal Health and Nutrition Survey (CLHNS) Cohort. Diabetes 2008, 57:1987-1991.

14. Frayling TM, Timpson NJ, Weedon MN, Zeggini E, Freathy RM, Lindgren CM, Perry JR, Elliott KS, Lango $H$, Rayner NW, et al: A common variant in the FTO gene is associated with body mass index and predisposes to childhood and adult obesity. Science 2007, 316:889-894.

15. Scuteri A, Sanna S, Chen WM, Uda M, Albai G, Strait J, Najjar S, Nagaraja R, Orru M, Usala G, et al: Genome-wide association scan shows genetic variants in the FTO gene are associated with obesity-related traits. PLOS Genet 2007, 3:e115.

16. Dina C, Meyre D, Gallina S, Durand E, Korner A, Jacobson P, Carlsson LM, Kiess W, Vatin V, Lecoeur C, et al: Variation in FTO contributes to childhood obesity and severe adult obesity. Nat Genet 2007, 39:724-726.

17. Altshuler D, Hirschhorn JN, Klannemark M, Lindgren CM, Vohl MC, Nemesh J, Lane CR, Schaffner SF, Bolk S, Brewer C, et al: The common PPARgamma Pro12Ala polymorphism is associated with decreased risk of type 2 diabetes. Nat Genet 2000, 26:76-80.

18. Gloyn AL, Weedon MN, Owen KR, Turner MJ, Knight BA, Hitman G, Walker M, Levy JC, Sampson M, Halford S, et al: Large-scale association studies of variants in genes encoding the pancreatic beta-cell KATP channel subunits Kir6.2 (KCNJ11) and SUR1 (ABCC8) confirm that the KCNJ11 E23K variant is associated with type 2 diabetes. Diabetes 2003, 52:568-572.

19. Cauchi S, El Achhab Y, Choquet H, Dina C, Krempler F, Weitgasser $R$ Nejjari C, Patsch W, Chikri M, Meyre D, Froguel P: TCF7L2 is reproducibly associated with type 2 diabetes in various ethnic groups: a global metaanalysis. J Mol Med 2007, 85:777-782.

20. Hertel JK, Johansson S, Raeder H, Midthjell K, Lyssenko V, Groop L, Molven A, Njolstad PR: Genetic analysis of recently identified type 2 diabetes loci in 1,638 unselected patients with type 2 diabetes and 1,858 control participants from a Norwegian population-based cohort (the HUNT study). Diabetologia 2008, 51:971-977.

21. Knuiman MW, Cullen KJ, Bulsara MK, Welborn TA, Hobbs MS: Mortality trends, 1965 to 1989 , in Busselton, the site of repeated health surveys and interventions. Aust J Public Health 1994, 18:129-135.

22. Knuiman MW, Jamrozik K, Welborn TA, Bulsara MK, Divitini ML, Whittall DE: Age and secular trends in risk factors for cardiovascular disease in Busselton. Aust J Public Health 1995, 19:375-382.

23. James AL, Palmer LJ, Kicic E, Maxwell PS, Lagan SE, Ryan GF, Musk AW: Decline in lung function in the Busselton Health Study: the effects of asthma and cigarette smoking. Am J Respir Crit Care Med 2005, 171:109-114.

24. Webster RJ, Warrington NM, Weedon MN, Hattersley AT, McCaskie PA, Beilby JP, Palmer LJ, Frayling TM: The association of common genetic variants in the APOA5, LPL and GCK genes with longitudinal changes in metabolic and cardiovascular traits. Diabetologia 2009, 52:106-114. 
25. Chapman CM, Palmer LJ, McQuillan BM, Hung J, Burley J, Hunt C, Thompson PL, Beilby JP: Polymorphisms in the angiotensinogen gene are associated with carotid intimal-medial thickening in females from a community-based population. Atherosclerosis 2001, 159:209-217.

26. HOMA Calculator. Book HOMA Calculator (Editor ed.^eds.) City: University of Oxford 2004.

27. Levy JC, Matthews DR, Hermans MP: Correct homeostasis model assessment (HOMA) evaluation uses the computer program. Diabetes Care 1998, 21:2191-2192.

28. Matthews DR, Hosker JP, Rudenski AS, Naylor BA, Treacher DF, Turner RC: Homeostasis model assessment: insulin resistance and beta-cell function from fasting plasma glucose and insulin concentrations in man. Diabetologia 1985, 28:412-419.

29. Ihaka R, Gentleman R: R: A language for data analysis and graphics. Journal of Computational and Graphical Statistics 1996, 5:299-314.

30. Abecasis GR, Cardon LR, Cookson WO: A general test of association for quantitative traits in nuclear families. Am J Hum Genet 2000, 66:279-292.

31. Laird NM, Ware JH: Random-effects models for longitudinal data. Biometrics 1982, 38:963-974.

32. Gauderman WJ: Sample size requirements for association studies of gene-gene interaction. Am J Epidemiol 2002, 155:478-484.

33. Ruchat SM, Elks CE, Loos RJ, Vohl MC, Weisnagel SJ, Rankinen T, Bouchard C, Perusse L: Association between insulin secretion, insulin sensitivity and type 2 diabetes susceptibility variants identified in genome-wide association studies. Acta Diabetol 2009, 46:217-226.

34. Wu Y, Li H, Loos RJ, Yu Z, Ye X, Chen L, Pan A, Hu FB, Lin X: Common variants in CDKAL1, CDKN2A/B, IGF2BP2, SLC30A8, and HHEX/IDE genes are associated with type 2 diabetes and impaired fasting glucose in a Chinese Han population. Diabetes 2008, 57:2834-2842.

35. Warodomwichit D, Arnett DK, Kabagambe EK, Tsai MY, Hixson JE, Straka RJ, Province M, An P, Lai CQ, Borecki I, Ordovas JM: Polyunsaturated fatty acids modulate the effect of TCF7L2 gene variants on postprandial lipemia. J Nutr 2009, 139:439-446.

36. Loos RJ, Franks PW, Francis RW, Barroso I, Gribble FM, Savage DB, Ong KK, O'Rahilly S, Wareham NJ: TCF7L2 polymorphisms modulate proinsulin levels and beta-cell function in a British Europid population. Diabetes 2007, 56:1943-1947.

37. Huertas-Vazquez A, Plaisier C, Weissglas-Volkov D, Sinsheimer J, CanizalesQuinteros S, Cruz-Bautista I, Nikkola E, Herrera-Hernandez M, DavilaCervantes A, Tusie-Luna T, et al: TCF7L2 is associated with high serum triacylglycerol and differentially expressed in adipose tissue in families with familial combined hyperlipidaemia. Diabetologia 2008, 51:62-69.

38. Cauchi S, Proenca C, Choquet H, Gaget S, De Graeve F, Marre M, Balkau B, Tichet J, Meyre D, Vaxillaire M, Froguel P: Analysis of novel risk loci for type 2 diabetes in a general French population: the D.E.S.I.R. study. J Mol Med 2008, 86:341-348.

39. Cauchi S, Meyre D, Choquet H, Dina C, Born C, Marre M, Balkau B, Froguel P: TCF7L2 variation predicts hyperglycemia incidence in a French general population: the data from an epidemiological study on the Insulin Resistance Syndrome (DESIR) study. Diabetes 2006, 55:3189-3192.

40. Sanghera DK, Ortega L, Han S, Singh J, Ralhan SK, Wander GS, Mehra NK, Mulvihill JJ, Ferrell RE, Nath SK, Kamboh MI: Impact of nine common type 2 diabetes risk polymorphisms in Asian Indian Sikhs: PPARG2 (Pro12Ala), IGF2BP2, TCF7L2 and FTO variants confer a significant risk. BMC Med Genet 2008, 9:59.

41. Ruchat SM, Rankinen T, Weisnagel SJ, Rice T, Rao DC, Bergman RN, Bouchard C, Perusse L: Improvements in glucose homeostasis in response to regular exercise are influenced by the PPARG Pro12Ala variant: results from the HERITAGE Family Study. Diabetologia 2010, 53:679-689.

42. Willer CJ, Bonnycastle LL, Conneely KN, Duren WL, Jackson AU, Scott LJ, Narisu N, Chines PS, Skol A, Stringham HM, et al: Screening of 134 single nucleotide polymorphisms (SNPs) previously associated with type 2 diabetes replicates association with 12 SNPs in nine genes. Diabetes 2007, 56:256-264.

43. Jaziri $R$, Lobbens $S$, Aubert $R$, Pean F, Lahmidi S, Vaxillaire M, Porchay I, Bellili N, Tichet J, Balkau B, et al: The PPARG Pro12Ala polymorphism is associated with a decreased risk of developing hyperglycemia over 6 years and combines with the effect of the APM1 G-11391A single nucleotide polymorphism: the Data From an Epidemiological Study on the Insulin Resistance Syndrome (DESIR) study. Diabetes 2006, 55:1157-1162.

44. Staiger H, Stancakova A, Zilinskaite J, Vanttinen M, Hansen T, Marini MA, Hammarstedt A, Jansson PA, Sesti G, Smith U, et al: A candidate type 2 diabetes polymorphism near the HHEX locus affects acute glucosestimulated insulin release in European populations: results from the EUGENE2 study. Diabetes 2008, 57:514-517.

45. Deeb SS, Fajas L, Nemoto M, Pihlajamaki J, Mykkanen L, Kuusisto J, Laakso M, Fujimoto W, Auwerx J: A Pro12Ala substitution in PPARgamma2 associated with decreased receptor activity, lower body mass index and improved insulin sensitivity. Nat Genet 1998, 20:284-287.

46. Nielsen EM, Hansen L, Carstensen B, Echwald SM, Drivsholm T, Glumer C, Thorsteinsson B, Borch-Johnsen K, Hansen T, Pedersen O: The E23K variant of Kir6.2 associates with impaired post-OGT serum insulin response and increased risk of type 2 diabetes. Diabetes 2003, 52:573-577.

47. Schwanstecher C, Meyer U, Schwanstecher M: K(IR)6.2 polymorphism predisposes to type 2 diabetes by inducing overactivity of pancreatic beta-cell ATP-sensitive $\mathrm{K}(+)$ channels. Diabetes 2002, 51:875-879.

48. Lyssenko V, Lupi R, Marchetti P, Del Guerra S, Orho-Melander M, Almgren P, Sjogren M, Ling C, Eriksson KF, Lethagen AL, et al: Mechanisms by which common variants in the TCF7L2 gene increase risk of type 2 diabetes. $J$ Clin Invest 2007, 117:2155-2163.

49. Saxena R, Gianniny L, Burtt NP, Lyssenko V, Giuducci C, Sjogren M, Florez JC, Almgren P, Isomaa B, Orho-Melander M, et al: Common single nucleotide polymorphisms in TCF7L2 are reproducibly associated with type 2 diabetes and reduce the insulin response to glucose in nondiabetic individuals. Diabetes 2006, 55:2890-2895.

50. Grarup N, Rose CS, Andersson EA, Andersen G, Nielsen AL, Albrechtsen A, Clausen JO, Rasmussen SS, Jorgensen T, Sandbaek A, et al: Studies of association of variants near the HHEX, CDKN2A/B, and IGF2BP2 genes with type 2 diabetes and impaired insulin release in 10,705 Danish subjects: validation and extension of genome-wide association studies. Diabetes 2007, 56:3105-3111.

51. Pascoe L, Tura A, Patel SK, Ibrahim IM, Ferrannini E, Zeggini E, Weedon MN, Mari A, Hattersley AT, McCarthy MI, et al: Common variants of the novel type 2 diabetes genes CDKAL1 and HHEX/IDE are associated with decreased pancreatic beta-cell function. Diabetes 2007, 56:3101-3104.

52. Staiger H, Machicao F, Stefan N, Tschritter O, Thamer C, Kantartzis K, Schafer SA, Kirchhoff K, Fritsche A, Haring HU: Polymorphisms within novel risk loci for type 2 diabetes determine beta-cell function. PLoS One 2007, 2:e832.

53. Abdul-Ghani MA, Tripathy D, DeFronzo RA: Contributions of beta-cell dysfunction and insulin resistance to the pathogenesis of impaired glucose tolerance and impaired fasting glucose. Diabetes Care 2006, 29:1130-1139.

54. Tabara Y, Osawa H, Guo H, Kawamoto R, Onuma H, Shimizu I, Takara Y, Nishida W, Yamamoto M, Makino H, et al: Prognostic significance of FTO genotype in the development of obesity in Japanese: the J-SHIPP study. Int J Obes (Lond) 2009.

\section{Pre-publication history}

The pre-publication history for this paper can be accessed here: http://www.biomedcentral.com/1471-2350/11/140/prepub

\section{doi:10.1186/1471-2350-11-140}

Cite this article as: Webster et al:: The longitudinal association of common susceptibility variants for type 2 diabetes and obesity with fasting glucose level and BMI. BMC Medical Genetics 2010 11:140. 